\title{
Optimization of Interval Fuzzy Time Series with Particle Swarm Optimization for Prediction Air Quality on Pekanbaru
}

\author{
${ }^{1}$ Fitri Insani, ${ }^{2}$ Ade Puspita Sari \\ 1,2 Departement of Informatics Engineering, Universitas Islam Negeri Sultan Syarif Kasim Riau \\ Email: ${ }^{1}$ fitri.insani@uin-suska.ac.id, ${ }^{2}$ ade.puspita.sari@students.uin-suska.ac.id
}

\begin{tabular}{l}
\hline \hline Article Info \\
\hline Article history: \\
Received Nov $20^{\text {th }}, 2019$ \\
Revised Jan $18^{\text {th }}, 2020$ \\
Accepted Mar $26^{\text {th }}, 2020$ \\
\hline Keyword: \\
Air Quality \\
Fuzzy Time Series \\
Optimization \\
Particle Swarm Optimization \\
Prediction \\
\end{tabular}

\begin{abstract}
Pekanbaru city have the most citizen in Riau province, which is 1.046.566 citizens with 105.941 unit vehicle. Environmental agency said that Pekanbaru city got bad air quality because of forest fire and exhaust emission gas from the vehicle. On that term, Pekanbaru city used Air Quality Monitoring System (AQMS) to display information through ISPU display board. This research intend to predict the next day air quality in Pekanbaru city using Fuzzy Time Series method which optimized with Particle Swarm Optimization. The prediction accuracy calculated by using Mean Absolute Percentage Error (MAPE) method which calculated by the result between actual data and prediction result. The input data is 729 data with 5 air quality index parameters, $\mathrm{PM}_{10}, \mathrm{SO}_{2}, \mathrm{CO}, \mathrm{O}_{3}$, and $\mathrm{NO}_{2}$. The output is prediction value for each air quality parameters. This FTS-PSO research testing has MAPE 18,3583\%. The best PSO parameters using in this research is 10 particle amount, 25 max iteration, and 0.6 inertia weight. The conclution of this research is FTS-PSO air quality prediction is quite accurate.
\end{abstract}

Copyright (C) 2020 Puzzle Research Data Technology

\author{
Corresponding Author: (10 pt) \\ Third Author, \\ Departement of Electrical and Computer Engineering, \\ National Chung Cheng University, \\ 168 University Road, Minhsiung Township, Chiayi County 62102, Taiwan, ROC. \\ Email: thirdauthor@uin-suska.ac.id
}

DOI: http://dx.doi.org/10.24014/ijaidm.v3i1.9298

\section{PENDAHULUAN}

Kota Pekanbaru merupakan salah satu kabupaten/ kota yang ada di Provinsi Riau. Berdasarkan hasil evaluasi kualitas udara yang dilakukan secara acak di seluruh kota di Indonesia, Badan Lingkungan Hidup Kota Pekanbaru menyatakan bahwa Pekanbaru memiliki kualitas udara yang tercemar. Pencemaran udara disebabkan oleh kasus kebakaran hutan dan lahan serta emisi gas buang kendaraan bermotor. Adapun penyebab lain dari pencemaran udara berasal dari transportasi, industri, perkantoran, perumahan, gunung meletus, kebakaran hutan, gas beracun, dan lain sebagainya [1]. Parameter pencemaran udara menurut PP No.41 tahun 1999 adalah Sulfur dioksida $\left(\mathrm{SO}_{2}\right)$, Karbon monoksida $(\mathrm{CO})$, Nitrogen dioksida $\left(\mathrm{NO}_{2}\right)$, Ozon $\left(\mathrm{O}_{3}\right)$, Hidro karbon (HC), PM10, PM2.5, TSP (debu), Pb (timah hitam), Dustfall (debu jatuh) [2]. Pencemaran udara memberikan dampak yang buruk bagi kesehatan sebagai mana badan kesehatan dunia (WHO) menyatakan setidaknya sekitar 7 juta jiwa meninggal setiap tahunnya akibat polusi udara. Pemantauan kualitas udara dilakukan dengan mengukur polutan setiap jam yang kemudian dihitung nilai rata-ratanya dalam satu hari dan ditampilkan pada hari itu tanpa adanya hasil prediksi mengenai kualitas udara keesokan harinya [3]. Keputusan Kepala Badan Pengendalian Dampak Lingkungan No: KEP-107/KABAPEDAL/11/1997 membagi kriteria kualitas udara menjadi baik, sedang, tidak sehat, sangat tidak sehat dan berbahaya.

Berikut adalah beberapa penelitian sebelumnya tentang prediksi kualitas udara diantaranya penelitian yang dilakukan oleh Ip, Vong, Yang dan Wong (2010) tentang prediksi polusi udara ambien harian dengan menggunakan metode Least Square Support Vector Machine (LS-SVM) dengan hasil penelitian memberikan nilai relative error untuk masing-masing parameter adalah 19,45\% untuk SPM, 7,12\% untuk $\mathrm{NO}_{2}$ dan 24,66\% untuk $\mathrm{O}_{3}$. Penelitan lainnya yaitu oleh Shaban, Kadri dan Rezk (2016) tentang pemantauan pencemaran udara 
di perkotaan dengan model prediksi menggunakan metode M5P dengan nilai RMSE 31,4 dan metode ANN dengan nilai RMSE 62,4. Berikutnya adalah penelitian oleh Ganesh, Reddy dan Arulmozhiyarman (2017) tentang prediksi indeks kualitas udara menggunakan metode sistem inferensi fuzzy mamdani dengan nilai RMSE 40,33 (Max-min), 37,79 (Sum-product) dan 39,99 (Max-product).

Prediksi juga dapat dilakukan dengan metode Fuzzy Time Series [4]. Metode Fuzzy Time Series memiliki kemampuan untuk menangkap pola dari data yang telah lalu guna memprediksi data yang akan datang. Fuzzy Time Series cocok digunakan untuk prediksi jangka panjang ataupun jangka pendek dengan nilai akurasi yang baik [5]. Beberapa penelitian tentang Fuzzy Time Series adalah sebagai berikut. Pertama penelitian oleh Abdullah (2011) tentang prediksi indeks gabungan Kuala Lumpur dengan menggunakan fuzzy time series dimana metode ini menghasilkan nilai MSE sebesar 42,44, RMSE 6,52 dan AFER 0,389\%. Berikutnya penelitian oleh Liu, Niu, He dan Li (2016) tentang memprediksi kata-kata yang sering dicari di situs Weibo menggunakan Fuzzy Time Series dengan nilai akurasi MAPE sebesar 2,32\%.

Terdapat faktor yang dapat mempengaruhi nilai akurasi metode Fuzzy Time Series yaitu panjang interval yang digunakan [6]. Panjang interval yang digunakan memiliki jarak yang terlalu jauh sehingga prediksi kurang optimal [7]. Untuk meningkatkan akurasi, Fuzzy Time Series (FTS) dapat dikombinasikan dengan metode optimasi salah satunya yaitu Particle Swarm Optimization (PSO) untuk mengoptimasi interval fungsi keanggotaan [8]. Beberapa penelitian yang melakukan optimasi terhadap metode FTS dengan PSO adalah sebagai berikut. Penelitian pertama yaitu oleh Sukmawan, Umbara dan Rohmawati (2015) tentang penggunaan PSO dan FTS untuk memprediksi indeks harga saham yang menghasilkan nilai MAPE 1,461\% dan MAD 3,73492. Selanjutnya penelitian oleh Datta dan Choudhury (2016) tentang klasifikasi data ragi berdasarkan model statistik multivarian dengan menggunakan PSO dan FTS dengan rata-rata eror 3,044. Penelitian terkait lainnya oleh Dwi, Darma dan Tibyani (2018) tentang penerapan PSO untuk mengoptimasi interval FTS untuk melakukan prediksi permintaan darah dengan hasil penelitian nilai MSE 60435,685 dan MAPE 7,50330\%.

Pada penelitian ini metode yang digunakan yaitu Particle Swarm Optimization untuk mengoptimasi interval fungsi keanggotaan Fuzzy Time Series untuk memprediksi kualitas udara di Pekanbaru. Penentuan kualitas udara di Pekanbaru berdasarkan parameter Sulfur dioksida $\left(\mathrm{SO}_{2}\right)$, Carbon monoksida (CO), Nitrogen dioksida $\left(\mathrm{NO}_{2}\right)$, Ozon $\left(\mathrm{O}_{3}\right)$ dan Particular matter (PM10) serta dikelompokkan berdasarkan Indeks Standar Pencemaran Udara (ISPU) dengan kategori baik, sedang, tidak sehat, sangat tidak sehat dan berbahaya.

\section{METODE PENELITIAN}

Tahapan atau langkah-langkah yang dilakukan pada penelitian optimasi interval Fuzzy Time Series menggunakan Particle Swarm Optimization untuk memprediksi kualitas udara di Kota Pekanbaru dapat dilihat pada Gambar 1.

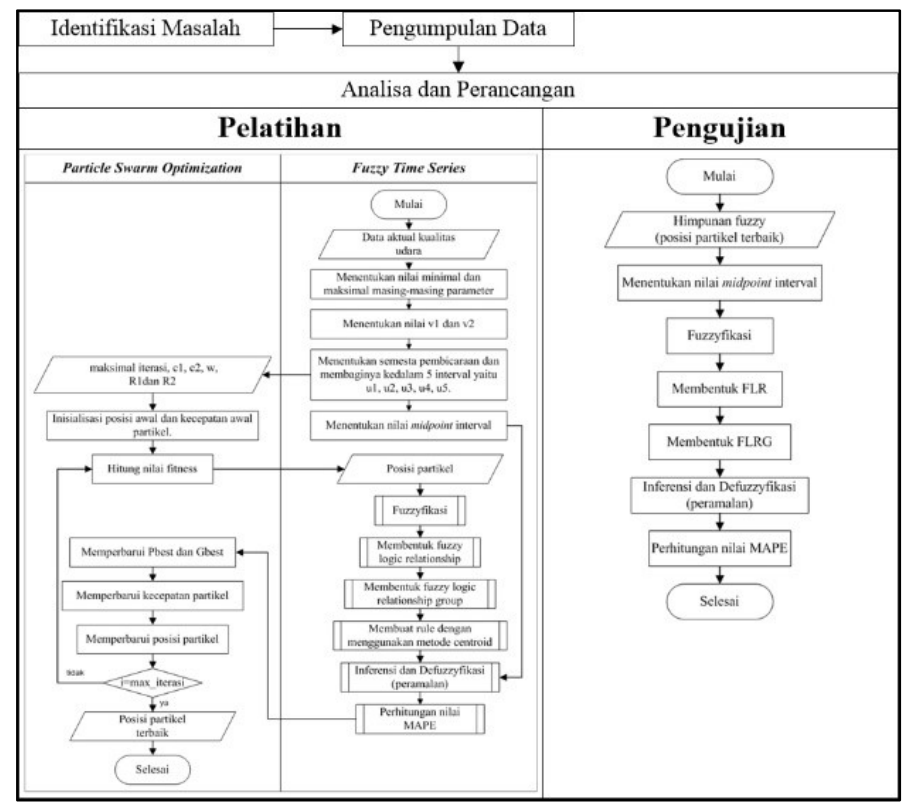

Gambar 1. Metode Penelitian

Tahapan awal yang dilakukan adalah mengidentifikasi masalah yaitu bagaimana mengoptimasi interval Fuzzy Time Series untuk memprediksi kualitas udara. Optimasi interval dilakukan dengan 
menggunakan metode Particle Swarm Optimization. Prediksi kualitas udara akan dilakukan dengan mentode Fuzzy Time Series. Berikut adalah penjelasan untuk masing-masing tahapan metode penelitian.

\subsection{Pengumpulan Data}

Data yang digunakan pada penelitian ini merupakan data harian udara Kota Pekanbaru pada tahun 2014-2015 yang diperoleh dari Laboratorium Udara Kota Pekanbaru. Parameter pengukuran kualitas udara yang digunakan adalah $\mathrm{NO}_{2}, \mathrm{SO}_{2}, \mathrm{CO}, \mathrm{PM}_{10}$, dan $\mathrm{O}_{3}$. Data kualitas udara yang digunakan pada penelitian ini berjumlah 729 data yang terdapat pada Tabel 1.

Tabel 1. Data Penelitian

\begin{tabular}{ccccccc}
\hline No & Tanggal & $\mathrm{PM}_{10}$ & $\mathrm{SO}_{2}$ & $\mathrm{CO}$ & $\mathrm{O}_{3}$ & $\mathrm{NO}_{2}$ \\
\hline 1 & $01 / 01 / 2014$ & 47 & 51 & 8 & 67 & 2 \\
2 & $02 / / 01 / 2014$ & 48 & 51 & 9 & 37 & 2 \\
3 & $03 / 01 / 2014$ & 37 & 51 & 9 & 26 & 2 \\
$\ldots$ & $\ldots$ & $\ldots$ & $\ldots$ & $\ldots$ & $\ldots$ & $\ldots$ \\
32 & $01 / 02 / 2014$ & 85 & 3 & 16 & - & 43 \\
33 & $02 / 02 / 2014$ & 65 & 0 & 9 & 70 & 30 \\
$\ldots$ & $\ldots$ & $\ldots$ & $\ldots$ & $\ldots$ & $\ldots$ & $\ldots$ \\
318 & $15 / 11 / 2014$ & 8 & 18 & 5 & 51 & 3 \\
319 & $16 / 11 / 2014$ & 3 & - & 4 & 48 & - \\
320 & $17 / 11 / 2014$ & 5 & - & 3 & 49 & 15 \\
$\ldots$ & $\ldots$ & $\ldots$ & $\ldots$ & $\ldots$ & $\ldots$ & $\ldots$ \\
705 & $07 / 12 / 2015$ & - & - & - & - & - \\
706 & $08 / 12 / 2015$ & 22 & 4 & 1 & 24 & 4 \\
$\ldots$ & $\ldots$ & $\ldots$ & $\ldots$ & $\ldots$ & $\ldots$ & $\ldots$ \\
728 & $30 / 12 / 2015$ & 10 & 4 & 0 & 14 & 3 \\
729 & $31 / 12 / 2015$ & 25 & 4 & 3 & 20 & 5 \\
\hline
\end{tabular}

\subsection{Analisa dan Perancangan}

Pada tahap analisa ini terbagi menjadi dua langkah yaitu pelatihan dan pengujian seperti terlihat pada Gambar 1. Pada proses pelatihan dilakukan pengoptimasian FTS menggunakan PSO. Adapun yang dioptimasi adalah interval himpunan fuzzy. Metode PSO digunakan untuk mencari nilai interval himpunan fuzzy. Metode FTS yang terdapat pada pelatihan ini digunakan untuk mencari nilai fitness pada PSO. Hasil dari proses pelatihan ini yaitu posisi partikel terbaik berupa nilai interval himpunan fuzzy yang akan digunakan untuk proses pengujian. Alur penerapan algoritma FTS-PSO untuk proses pelatihan pada penelitian ini adalah sebagai berikut:

a. Masukkan data kualitas udara sebagai data masukan metode FTS.

b. Menentukan semesta pembicaraan dan membaginya ke dalam 5 interval yaitu $\mathrm{U}_{1}, \mathrm{U}_{2}, \mathrm{U}_{3}, \mathrm{U}_{4}$, dan $\mathrm{U}_{5}$ dengan menggunakan persamaan berikut ini:

$$
\begin{aligned}
& U=(\text { batas bawah, batas atas }) \\
& U=(\text { Vmin }-V 1, V \max +V 2)
\end{aligned}
$$

c. Menentukan nilai midpoint interval dengan menggunakan persamaan berikut:

$$
m=\frac{\text { batas atas }+ \text { batas baw }}{2}
$$

d. Setelah mendapatkan semesta pembicaraan, selanjutnya masuk ke metode PSO.

e. Inisialisasi maksimal iterasi, jumlah partikel, nilai koefisien akselerasi (c1 dan c2), bobot inersia $(\omega)$, dan nilai random (R1 dan $\mathrm{R} 2)$.

f. Inisialisalisasi posisi awal dan kecepatan awal partikel. Posisi awal partikel adalah interval FTS yang telah diperoleh pada tahapan nomor 2. Kecepatan awal partikel adalah 0 .

g. Selanjutnya hitung nilai fitness masing-masing partikel dengan menggunakan metode FTS. Berikut ini adalah tahapan metode FTS untuk mencari nilai fitness:

i. Melakukan fuzzyfikasi terhadap data historis dengan menentukan fungsi keanggotaan $\left(\mathrm{A}_{1}, \mathrm{~A}_{2}\right.$, $\mathrm{A}_{3}, \mathrm{~A}_{4}$, dan $\mathrm{A}_{5}$ ) dan derajat keanggotannya dengan menggunakan persamaan berikut:

$$
\mu_{i j}=\left\{\begin{array}{rr}
1 & i=j \\
0,5 & j=i-1 \text { atau } i=1 \\
0 & \text { selain } i t u
\end{array}\right.
$$

IJAIDM Vol. 3, No. 1, March 2020: $36-41$ 
ii. Menentukan FLR berdasarkan hubungan data yang telah difuzzifikasi dengan data sebelumnya $\left(\mathrm{A}_{1} \rightarrow \mathrm{A}_{2}\right)$.

iii. Menyusun FLRG dengan mengumpulkan FLR yang telah ada berdasarkan current state yang $\operatorname{sama}\left(\mathrm{A}_{1} \rightarrow \mathrm{A}_{2}, \mathrm{~A}_{3}, \ldots, \mathrm{A}_{\mathrm{n}}\right)$.

iv. Membuat rule dengan menggunakan metode centroid untuk memperoleh solusi berupa nilai crisp. Langkah ini dilakukan dengan mengambil nilai titik tengah interval fuzzy.

v. Selanjutnya tahapan inferensi dan defuzzifikasi berdasarkan himpunan fuzzy yang diperoleh. Inferensi dilakukan dengan mengambil nilai maksimal derajat keanggotaan. Defuzzifikasi dilakukan dengan mengalikan nilai maksimal derajat keanggotaan dengan titik tengah interval fuzzy.

vi. Lakukan prediksi dengan menjumlahkan nilai defuzzifikasi dengan data historis.

vii. Menghitung nilai MAPE. Nilai MAPE yang diperoleh menjadi nilai fitness partikel. Berikut adalah persamaan MAPE:

$$
M A P E=\frac{\sum_{t=1}^{n}\left|\frac{X_{t}-F_{t}}{X_{t}}\right|}{n} \times 100 \%
$$

dengan;

$\mathrm{X}_{\mathrm{t}} \quad=$ data aktual pada periode ke-t

$\mathrm{F}_{\mathrm{t}} \quad=$ nilai prediksi pada periode ke- $\mathrm{t}$

$\mathrm{n} \quad=$ jumlah data

h. Selanjutnya memperbarui Pbest dan Gbest. Pbest ditentukan berdasarkan nilai fitness partikel pada iterasi ke-i dengan iterasi ke i-1. Nilai Gbest didapatkan dari Pbest terbaik dengan membandingkan nilai Pbest setiap iterasi.

i. Memperbarui kecepatan partikel dengan menggunakan persamaan berikut:

$$
\mathrm{V}_{\mathrm{k}+1}=\omega \cdot \mathrm{V}_{\mathrm{k}}+\mathrm{c}_{1} \cdot \mathrm{R}_{1} \cdot\left(\text { Pbest }_{\mathrm{k}}-\mathrm{X}_{\mathrm{k}}\right)+\mathrm{c}_{2} \cdot \mathrm{R}_{2} \cdot\left(\text { Gbest }_{\mathrm{k}}-\mathrm{X}_{\mathrm{k}}\right)
$$

dengan:

$\omega=$ inertia weight

$\mathrm{V}_{\mathrm{k}+1} \quad=$ kecepatan untuk posisi yang dituju

$\mathrm{V}_{\mathrm{k}} \quad=$ kecepatan untuk posisi sekarang (awal)

Pbest $_{\mathrm{k}} \quad=$ personal best

Gbest $_{\mathrm{k}}=$ global best

$\mathrm{c}_{1}, \mathrm{c}_{2}=$ learning rates (biasanya berupa konstanta $\mathrm{c} 1=2$ dan $\mathrm{c} 2=2$ )

$\mathrm{R}_{1}, \mathrm{R}_{2}=$ nilai acak antara 0 dan 1

$\mathrm{X}_{\mathrm{k}} \quad=$ posisi sekarang

j. Memperbarui posisi partikel dengan menggunakan persamaan berikut:

$$
X_{j(i)}=X_{j(i-1)}+V_{j(i)}
$$

dengan;

$$
\begin{array}{ll}
\mathrm{j} & =1,2,3, \ldots, \mathrm{n} . \\
\mathrm{X}_{\mathrm{j}(\mathrm{i})} & =\text { posisi baru } \\
\mathrm{X}_{\mathrm{j}(\mathrm{i}-1)} & =\text { posisi sebelumnya } \\
\mathrm{V}_{\mathrm{j}(\mathrm{i})} & =\text { kecepatan baru }
\end{array}
$$

k. Lakukan langkah 5 sampai 9 hingga mendapatkan posisi partikel terbaik.

Pada tahap pengujian dilakukan prediksi terhadap kualitas udara di Kota Pekanbaru dengan menggunakan metode FTS. Prediksi dilakukan dengan menggunakan interval himpunan fuzzy yang diperoleh dari tahap pelatihan. Berikut adalah tahapan pengujian FTS:

a. Menjadikan posisi partikel terbaik PSO menjadi interval fuzzy.

b. Menentukan nilai midpoint interval terbaik dengan menggunakan persamaan 3 .

c. Menentukan fuzzyfikasi.

d. Membentuk FLR berdasarkan hubungan antar data $\left(\mathrm{x}_{\mathrm{i}-1} \rightarrow \mathrm{x}_{\mathrm{i}}\right)$ yang telah difuzzyfikasi.

e. Membentuk FLRG berdasarkan current state yang pada FLR. 
f. Melakukan inferensi dan defuzzifikasi. Kemudian lakukan prediksi dengan menjumlahkan hasil defuzzifikasi dengan data historis.

g. Perhitungan nilai MAPE dengan menggunakan persamaan 5. Nilai MAPE pada tahapan pengujian ini merupakan nilai error dari penerapan metode FTS-PSO.

\section{HASIL DAN ANALISA}

Hasil dari pengukuran kualitas udara dengan melakukan optimasi terhadap interval Fuzzy Time Series terlebih dahulu dengan data penelitian sebanyak 729 data dapat dilihat pada Tabel 2.

Tabel 2. Hasil Prediksi Kualitas Udara

\begin{tabular}{ccccccc}
\hline No. & Tanggal & $\mathbf{P M}_{\mathbf{1 0}}$ & $\mathbf{S O}_{\mathbf{2}}$ & $\mathbf{C O}$ & $\mathbf{O}_{\mathbf{3}}$ & $\mathbf{N O}_{\mathbf{2}}$ \\
\hline 1 & $22 / 12 / 2015$ & 481,8570 & 56,1822 & 109,6695 & 137,0000 & 75,2860 \\
2 & $23 / 12 / 2015$ & 477,0455 & 60,7277 & 99,9809 & 120,8634 & 66,0064 \\
3 & $24 / 12 / 2015$ & 485,1822 & 45,3506 & 105,7733 & 149,6102 & 88,4746 \\
4 & $25 / 12 / 2015$ & 477,1430 & 45,4025 & 109,2733 & 150,1102 & 64,4025 \\
5 & $26 / 12 / 2015$ & 492,5201 & 38,2595 & 81,6494 & 176,0847 & 83,1303 \\
6 & $27 / 12 / 2015$ & 488,9809 & 50,8379 & 104,5265 & 157,2140 & 81,0265 \\
7 & $28 / 12 / 2015$ & 495,5847 & 34,0000 & 103,4354 & 159,8443 & 85,6822 \\
8 & $29 / 12 / 2015$ & 447,5191 & 39,0000 & 108,3188 & 125,3506 & 58,4025 \\
9 & $30 / 12 / 2015$ & 475,5720 & 53,6822 & 99,1886 & 120,8634 & 87,6695 \\
10 & $31 / 12 / 2015$ & 463,3634 & 54,0328 & 105,4354 & 129,4545 & 64,2987 \\
\hline
\end{tabular}

Pada penelitian ini dilakukan pengujian terhadap kombinasi parameter PSO yaitu jumlah partikel, maksimal iterasi dan nilai bobot inersia. Hasil pengujian kombinasi parameter PSO dapat dilihat pada Tabel 3.

Tabel 3. Hasil Pengujian Komninasi Parameter

\begin{tabular}{cccc}
\hline Jumlah Partikel & Maksimal Iterasi & Bobot Inersia & Rata-rata MAPE (\%) \\
\hline \multirow{2}{*}{25} & 0,5 & $18,5646 \%$ \\
\multirow{2}{*}{25} & & 0,6 & $18,9198 \%$ \\
& \multirow{2}{*}{50} & 0,7 & $21,2441 \%$ \\
& & 0,5 & $18,3583 \%$ \\
& \multirow{2}{*}{25} & 0,6 & $19,5284 \%$ \\
& & 0,7 & $20,9239 \%$ \\
\hline \multirow{2}{*}{20} & \multirow{2}{*}{50} & 0,5 & $18,9795 \%$ \\
& & 0,6 & $19,0094 \%$ \\
& & 0,7 & $20,7159 \%$ \\
& & 0,5 & $19,6580 \%$ \\
& & 0,6 & $20,5899 \%$ \\
\end{tabular}

Berdasarkan hasil pengujian kombinasi parameter nilai MAPE terkecil yang diperoleh yaitu $18,3583 \%$ dengan kombinasi parameter yang digunakan yaitu maksimal iterasi 50 , jumlah partikel 10, dan nilai bobot inersia 0,5 .

\section{KESIMPULAN}

Berdasarkan hasil penelitian yang telah dilakukan, diperoleh beberapa kesimpulan dari penerapan optimasi interval Fuzzy Time Series dengan menggunakan Particle Swarm Optimization untuk memprediksi kualitas udara di Kota Pekanbaru adalah sebagai berikut:

1. Pengujian akurasi dilakukan dengan menggunakan MAPE dengan hasil nilai error sebesar $18,3583 \%$ dengan jumlah data 729 dan memiliki 5 parameter.

2. Berdasarkan hasil pengujian dengan kombinasi parameter PSO dapat ditarik kesimpulan bahwasannya semakin besar nilai bobot inersia $(\omega)$ yang digunakan, maka akan semakin besar nilai error prediksi yang dihasilkan.

\section{REFERENSI}

[1] Aditama, P. D. T. Y. (2014). Dampak Kesehatan Akibat Polusi Udara. Retrieved July 26, 2018, from http://simp2p.kemkes.go.id/blog/2014/04/dampak-kesehatan-akibat-polusi

[2] Peraturan Pemerintah No.41 (1999).

[3] Arifien, N. F., Arifin, S., Widjiantoro, B. L., \& Aisjah, A. S. (2012). Prediksi Kadar Polutan Dengan Menggunakan Jaringan Syaraf Tiruan ( JST ) Untuk Pemantauan, 1-11.

[4] Hasbiollah, M., \& Hakim, R. F. (2015). Peramalan konsumsi gas indonesia menggunakan algoritma, (2009), 508-518.

[5] Admirani, I. (2014). Penerapan Metode Fuzzy Time Series Untuk Prediksi Laba Pada Perusahaan, 19-

IJAIDM Vol. 3, No. 1, March 2020: $36-41$ 
31.

[6] Dwi, A. A. R., Setiawan, B. D., \& Tibyani. (2018). Optimasi Interval Fuzzy Time Series Menggunakan Particle Swarm Optimization pada Peramalan Permintaan Darah: Studi Kasus Unit Transfusi Darah Cabang - PMI Kota Malang, 2(7), 2770-2779.

[7] Mandariansah, T., Setiawan, B. D., \& Wihandika, R. C. (2018). Optimasi Fuzzy Time Series Untuk Peramalan Kebutuhan Hidup Layak Kota Kediri Dengan Menggunakan Algoritme Genetika, (May).

[8] Wang, H., Zhao, L., Du, W., \& Qian, F. (2011). A hybrid method for identifying T-S fuzzy models, 1115.

\section{BIBLIOGRAFI PENULIS}

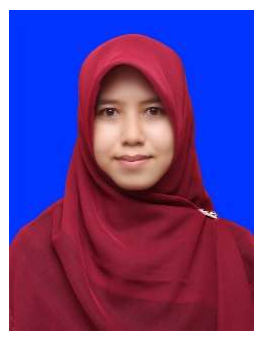

Penulis bernama Fitri Insani dilahirkan di Pekanbaru pada 3 Juni 1987. Penulis berprofesi sebagai dosen di jurusan Teknik Informatika UIN Sultan Syarif Kasim Riau.

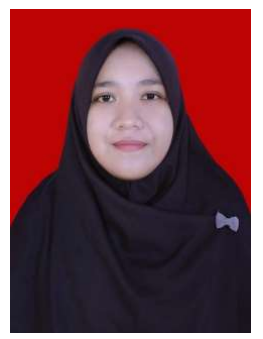

Penulis bernama Ade Puspita Sari yang lahir pada tanggal 25 Juni 1995 di Pekanbaru. Mahasiswa Teknik Informatika UIN SUSKA Riau. E-mail penulis yaitu ade.puspita.sari@students.uin-suska.ac.id. 